Journal of

Marine Science and Engineering

ISSN 2077-1312

www.mdpi.com/journal/jmse

Article

\title{
Modeling Near-Surface Suspended Sediment Concentration in the English Channel
}

Nicolas Guillou ${ }^{1, *}$, Aurélie Rivier ${ }^{1,2}$, Francis Gohin ${ }^{2}$ and Georges Chapalain ${ }^{1}$

${ }^{1}$ Laboratoire de Génie Côtier et Environnement, DTEMF/DS, Cerema, Technopôle Brest-Iroise, BP 5, 29280 Plouzané, France; E-Mails: aurelie.rivier@ifremer.fr (A.R.); georges.chapalain@ cerema.fr (G.C.)

2 ODE-DYNECO-PELAGOS, Ifremer, Centre de Bretagne, Technopôle Brest-Iroise, 29280 Plouzané, France; E-Mail: francis.gohin@ifremer.fr

* Author to whom correspondence should be addressed; E-Mail: nicolas.guillou@ cerema.fr; Tel.: +33-(0)-2-98-05-67-39; Fax: +33-(0)-2-98 05-67-21.

Academic Editor: Billy Edge

Received: 13 February 2015 / Accepted: 21 April 2015 / Published: 5 May 2015

\begin{abstract}
The present study investigates the performances of the three-dimensional multicomponent hydro-sedimentary model ROMS (Regional Ocean Modeling System) to predict near-surface suspended sediment concentrations (SSC) in the English Channel (western Europe). Predictions are assessed against satellite-retrieved observations from raw MODIS and MERIS images for the year 2008 characterized by the highest availability of cloud-free data. Focus is put on improvements obtained with: (1) SSC inputs at the open boundaries; and (2) simple parameterizations of the settling velocity and the critical shear stress. Sensitivity studies confirm the importance of the advection of fine-grained suspended sediments in the central waters of the English Channel exhibiting benefits of refined SSC estimations along the sea boundaries. Improvements obtained with modified formulations of the settling velocity and the critical shear stress finally suggest possible seasonal influences of biological activity and thermal stratification on near-surface SSC.
\end{abstract}

Keywords: ROMS; satellite; MERIS; MODIS; tide; wave 


\section{Introduction}

Quantification of suspended sediment concentration (SSC) is very important for several ecological and engineering problems of continental shelf ecosystems. Major concerns include: (1) evaluations of light available for photosynthesis and biological primary production; (2) assessment of water quality in relation to the transport of polluting substances; or (3) investigation of coastal morphological changes induced by human activities. A narrow arm of the North Atlantic ocean tapering eastward to its junction with the North Sea at the Dover Strait, the English Channel (Figure 1) is recognized as a region of strong tidal and wave regimes with intense associated bed erosion and suspended sediment transport, as exhibited in satellite images during winter energetic periods [1] (Figure 2).
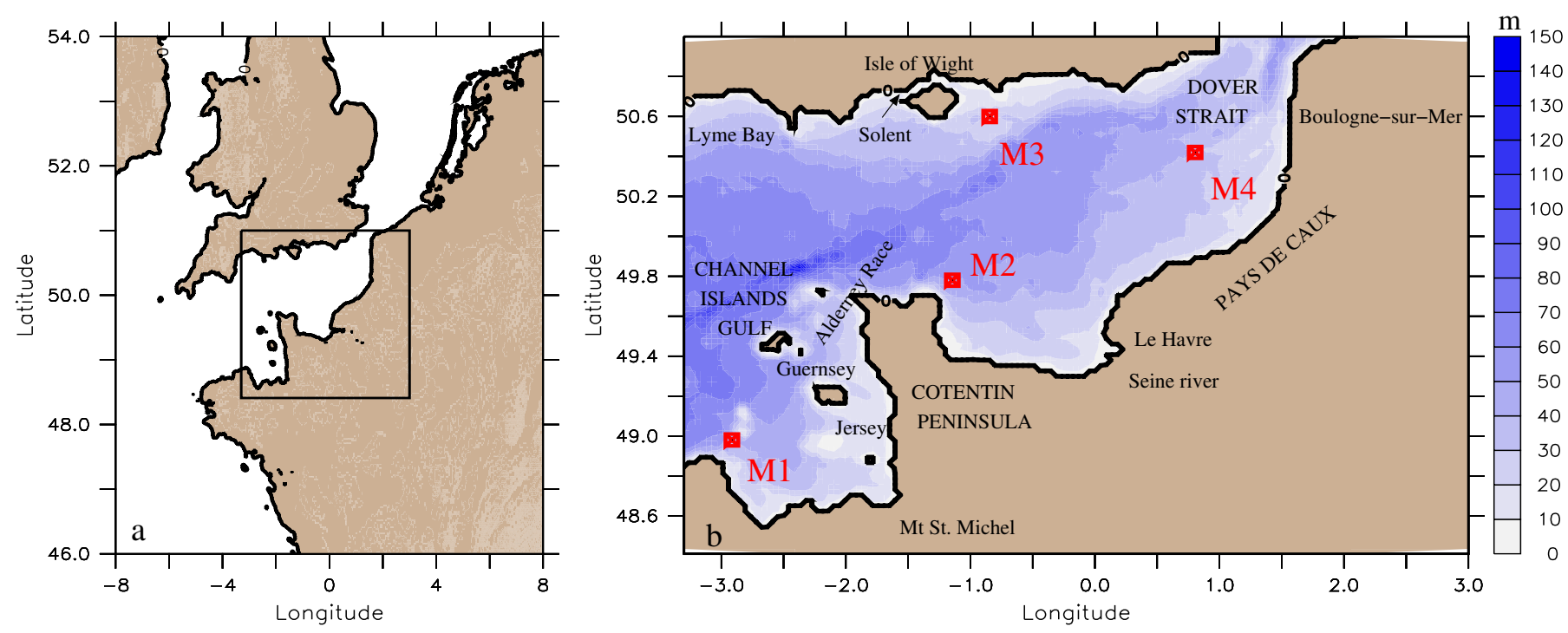

Figure 1. (a) Location of the English Channel on the northwestern European continental shelf; (b) Bathymetry of the computational domain with the locations of Points M1-M4.
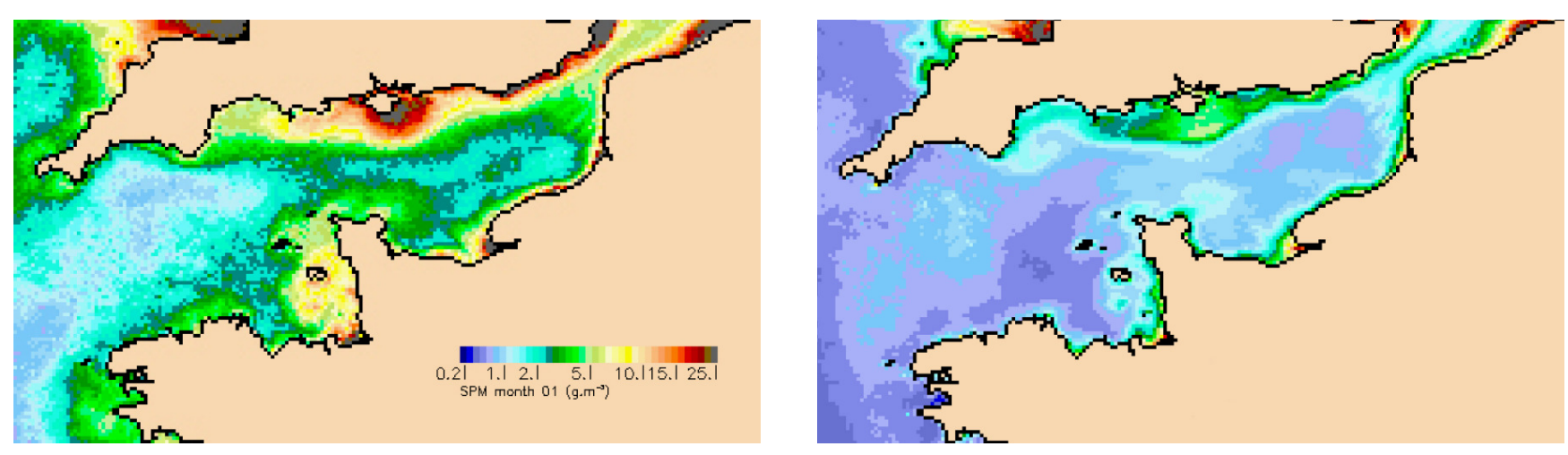

Figure 2. Averaged near-surface suspended sediment concentration (SSC) from MODIS satellite images over the period 2003-2009 for the months of (left) January and (right) August (Ifremer, Francis Gohin).

Numerous numerical models have been implemented in the English Channel to investigate SSC dynamics under the influences of tides and waves. Qualitative estimations were initially conducted 
correlating sediment-transport pathways with the directions of predicted maximum tidal bed stresses [2]. Confirming previous studies based on morphological (asymmetry of bedforms) and sedimentological observations [3], associated predictions exhibited a causal relationship between surficial sediment deposits and tidal current strength. In the English Channel, granule and pebble deposits are thus found in areas of maximum tidal bed shear stress of the Channel Islands Gulf, the central cross-section between the Isle of Wight and the Cotentin Peninsula or the central Dover Strait, whereas fine sediments prevail in bays and estuaries (e.g., Lyme Bay, Bay of Seine) (Figure 3). These simplified investigations were followed by off-line computing approaches combining outputs from bi-dimensional horizontal (2DH) hydrodynamic models with empirical sand transport formulae [4-6]. Numerical results refined the quantifications of tidal sediment transport pathways through the Wight-Cotentin section and the Dover Strait. More complex fully-three-dimensional (3D) computations were finally adopted to assess the consequences of local and advection-dispersion-controlled remote resuspensions on total SSC in tide-dominated conditions $[7,8]$ and stormy wave regimes $[9,10]$. Validated against in situ observations, these numerical studies remained, however, restricted to the vicinity of measurement sites.

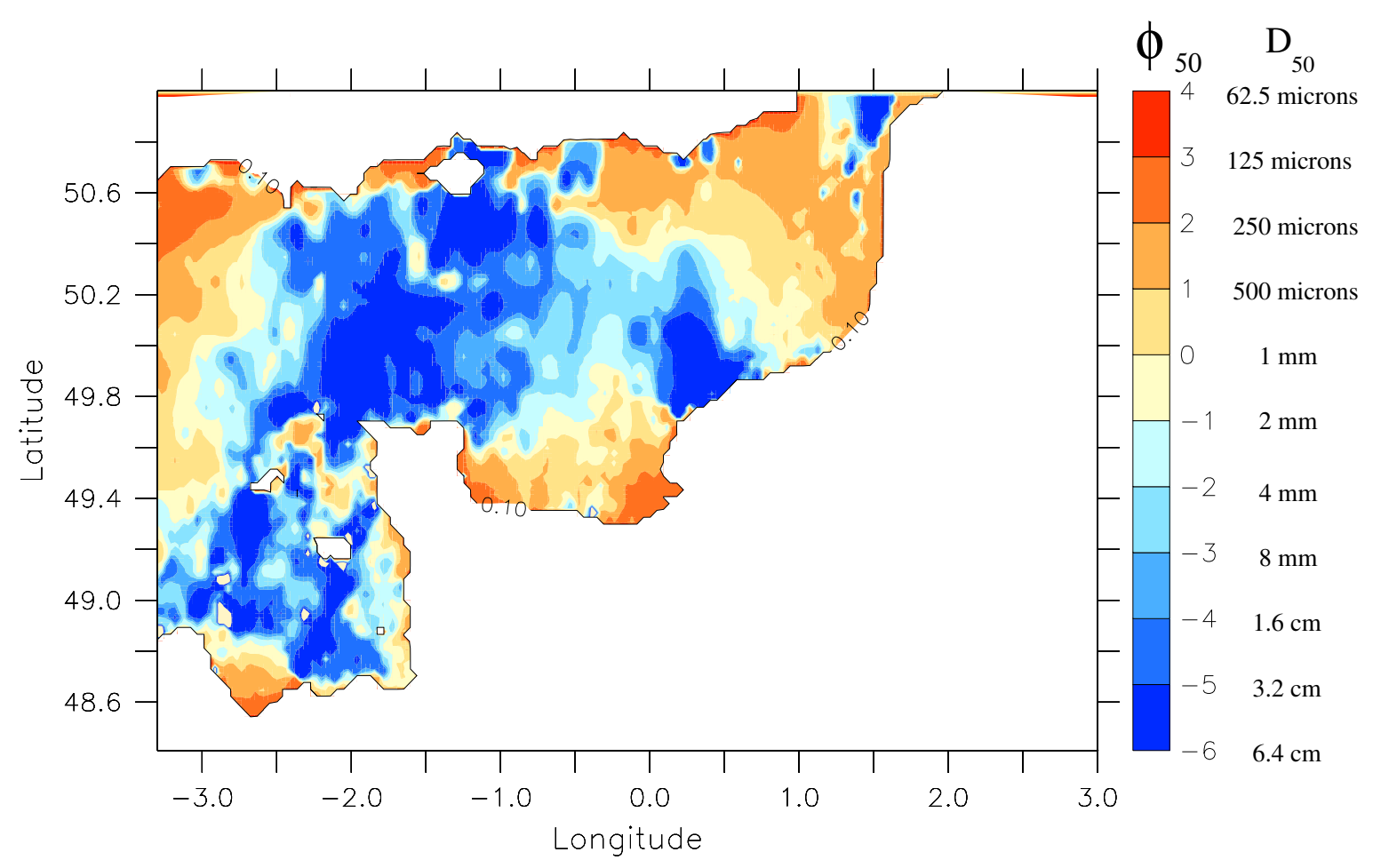

Figure 3. Interpolated median sieve diameter expressed in Wentworth's grain-size scale $\phi_{50}=-\log _{2}\left(D_{50}\right)$ (with $D_{50}$ in $\mathrm{mm}$ ).

In spite of strong dependency with cloud coverage and low time resolutions, remote-sensing images of near-surface SSC constitute an interesting dataset to assess model performances at the scale of the English Channel [1]. Whereas satellite data are evidence of clear-sky conditions, the observed signal integrates seasonal variations induced by major climatological conditions [11], as well as finer temporal modulations, such as spring-neap tidal signatures [12]. Nevertheless, whereas advanced modeling systems successfully approach major observed SSC patterns at the scale of the northwestern European shelf $[13,14]$, no further refined investigations have specifically focused on the English Channel. 
The purpose of the present study is to extend these comparisons relying on a fully-3D multicomponent modeling system integrating the major hydrodynamic forcings of tide and waves, associated non-linear interactions in the bottom boundary layer and the consequences in terms of suspended sediment transport with a realistic heterogeneous distribution of bottom sediments (Section 2). Predictions are assessed against satellite-retrieved observations of near-surface SSC during the year 2008 characterized by the highest availability of cloud-free observations (Section 3.1). Focus is placed on the improvements of the numerical results obtained with: (1) SSC inputs at the open boundaries (Section 3.2); and (2) simple parameterizations of the settling velocity and the critical shear stress (Section 3.3). Two sources of OBCs (Open Boundary Conditions) are considered based on: (1) monthly climatologies derived from satellite observations; and (2) daily predictions issued from a new statistical model [12] integrating the variability of resuspension events in relation to site-specific explanatory variables. Sensitivity studies confirm the importance of the advection of fine-grained suspended sediments in the offshore central waters exhibiting the benefits of refined SSC estimations along the sea boundaries. Improvements reached with modified formulations of the settling velocity and the critical shear stress finally suggest possible seasonal influences of the biological activity and the thermal stratification on near-surface SSC in the English Channel.

\section{Materials and Methods}

\subsection{Satellite Images}

Remote sensing data of near-surface SSC are derived from observed MODIS/AQUA (Moderate Resolution Imaging Spectroradiometer, NASA) and MERIS (Medium Resolution Imaging Spectrometer, ESA) reflectances processed using the semi-analytical algorithm developed by Gohin [1]. The procedure is briefly detailed hereafter. A simple equation of radiative transfer is considered to express reflectances from absorption and backscattering coefficients of pure sea water and concentrations of phytoplankton and non-algal particles. Phytoplankton biomass is first assumed to be proportional to the concentration of chlorophyll-a (Chl-a) obtained by application of two look-up tables to spectral remote-sensing reflectances [15]. The concentration of non-algal particles, here assumed as the total SSC, is then obtained by inverting the equation of radiative transfer. This algorithm, initially built on a backscattering coefficient at $550 \mathrm{~nm}$ [16], performed relatively well in moderately turbid waters, but tended to underestimate concentrations in the most turbid regions. A second channel at $670 \mathrm{~nm}$ has thus been added by Gohin [1] to integrate the highest concentrations. If the estimated concentration is lower than $4 \mathrm{mg}^{-1}$ for both channels, the resulting value derives from the backscattering coefficient at $550 \mathrm{~nm}$. Otherwise, the treatment relies on the channel at $670 \mathrm{~nm}$.

Data issued from this new method compare relatively well with in situ measurements at French coastal stations, including the offshore gradients of near-surface SSC off Boulogne-sur-Mer in the Dover Strait. Recent comparisons conducted by Sykes and Barcelia [14] at four buoys of the CEFAS (Centre for Environment, Fisheries and Aquaculture Science) network confirm also the performances of the algorithm in the northwestern European shelf seas. 
The final product has been available since 2002 at a daily frequency between 09:00 a.m. and 02:00 p.m. and a spatial resolution of $1.2 \mathrm{~km}$ over the IBI (Ireland, Biscay, Iberian) area through the MyOcean website [17].

\subsection{Numerical Model}

Modeling is based on the 3D multicomponent sediment transport model ROMS (Regional Ocean Modeling System) [18,19]. Principal model assumptions concern: (1) the flow, which is assumed turbulent over a rough bed; (2) the sedimentary particle assemblage, which is made of $N_{p}$ cohesionless spherical quartz components; and (3) the water-sediment mixture, considered not to be affected by the interactions between solid particles.

\subsubsection{Hydrodynamic Module}

The hydrodynamic module solves the Reynolds-averaged Navier-Stokes (RANS) equations derived using the hydrostatic and Boussinesq's approximations. The horizontal eddy viscosity $\nu_{H}$ is parameterized following Smagorinsky [20]. The vertical eddy viscosity is expressed as $\nu_{T}=0.4 \sqrt{2 k} l$, where $k$ is the turbulent kinetic energy and $l$ is the mixing length. These turbulent moments are computed with the generic length scale (GLS) method [21] solving a pair of transport equations for $k$ and $k l$, respectively.

The momentum and turbulent equations are subjected to vertical conditions based on appropriate formulations of sea-surface and bottom roughness parameters. The sea-surface drag coefficient is computed according to Fairall et al. [22], while bed roughness integrates the effect of the interactions between wave and current bottom boundary layers on the basis of the parameterization proposed by Soulsby et al. [23]. Coastal lateral boundaries are considered as impregnable walls. On the open sea boundaries, free-surface and normal depth-averaged currents are imposed with the iterative scheme proposed by Flather [24], while tangential velocity components are applied according to Chapman [25]. Zero gradient conditions are finally considered for the 3D velocities and the turbulent parameters $k$ and $l$.

The set of equations is expressed in spherical orthogonal curvilinear coordinates in the horizontal and stretched terrain following $\sigma$-coordinates in the vertical. Further details about the hydrodynamic module, its mathematical expression, as well as its numerical resolution are available in Haidvogel et al. [26].

\subsubsection{Sediment Transport Module}

The instantaneous volumetric concentration $C_{i}$ of each individual class subscripted $i$, with $i \in\left[1, N_{p}\right]$, is interpreted as an arbitrary scalar quantity satisfying a 3D advection-diffusion transport equation of the following form:

$$
\frac{\partial C_{i}}{\partial t}+\nabla_{\mathbf{h}} \cdot\left(C_{i} \mathbf{u}\right)+\frac{1}{H} \frac{\partial}{\partial \sigma}\left[\left(\tilde{w}-w_{s i}\right) C_{i}\right]=\frac{1}{H} \frac{\partial}{\partial \sigma}\left(\frac{\lambda_{T}}{H} \frac{\partial C_{i}}{\partial \sigma}\right)+\nabla_{\mathbf{h}} \cdot\left(\lambda_{H} \nabla_{\mathbf{h}}\left(C_{i}\right)\right)
$$

where $\nabla_{\mathbf{h}}$ is the horizontal gradient operator, $t$ denotes time, $\mathbf{u}$ is the horizontal velocity component, $H$ is the instantaneous total water depth, $\tilde{w}$ is the vertical velocity normal to $\sigma$-planes, $\lambda_{H}$ is the horizontal 
eddy diffusivity parameterized following Smagorinsky [20], $\lambda_{T}$ is the vertical eddy diffusivity expressed as $\lambda_{T}=0.49 \sqrt{k} l$ and $w_{s i}$ is the settling velocity of particles from size class $i$.

A zero mass flux condition is imposed at the free surface, while the bottom boundary condition specifies the net flux through the bottom level of suspension:

$$
w_{s i} C_{i}+\frac{\lambda_{T}}{H} \frac{\partial C_{i}}{\partial \sigma}=D_{i}-E_{i}
$$

where $D_{i}$ is the deposition rate due to settling and $E_{i}$ is the upward turbulent entrainment rate. The deposition rate is simply expressed as $D_{i}=w_{s i} C_{i}^{b o t}$ with $C_{i}^{b o t}$ the near-bed concentration [27]. The entrainment rate is parameterized according to Ariathurai and Arulanandan [28]:

$$
E_{i}=f_{i}(1-p) E_{0}\left[\max \left(\frac{\tau_{c, \omega}-\tau_{c r, i}}{\tau_{c r, i}}, 0\right)\right]
$$

where $f_{i}$ is the volumetric fraction of sediments in size class $i$ in the bed surface layer, $p$ is the bed sediment porosity taken as equal to $p=0.36, \tau_{c, \omega}$ is the total maximum wave and current bottom shear stress [23] and $\tau_{c r, i}$ is the critical shear stress value of the motion of particles in size class $i . E_{0}$ is an empirical entrainment rate taken here to be equal to $E_{0}=5 \times 10^{-4} \mathrm{~kg} \mathrm{~m}^{-2} \mathrm{~s}^{-1}$ for each grain-size class considered. The value here retained falls in the range $\left[10^{-4} ; 10^{-2} \mathrm{~kg} \mathrm{~m}^{-2} \mathrm{~s}^{-1}\right]$ obtained from a review of parameterizations adopted in the literature [29,30]. The mass of each sediment class available for transport is limited to the mass available in the active surface layer whose thickness is determined with the relation of Harris and Wiberg [31]. The sediment bed is discretized into $N_{c}$ layers with thicknesses and availabilities of sedimentary particles modified at each time step in relation to erosion and deposition fluxes at the seabed interface. Further details on this multi-level bed framework are available in Warner et al. [18].

\subsubsection{SSC Open Boundary Conditions}

A zero normal gradient condition is considered for unknown SSC inputs along the open sea boundaries, while a scalar condition specifies the imposed concentrations. Two OBC sources are considered based on: (1) monthly climatologies derived from satellite observations; and (2) daily predictions issued from a new statistical model. Monthly climatologies are issued from processing of MODIS reflectances performed by Gohin [1] for the period 2003-2009 over the northwestern European shelf. Daily predictions are obtained with the statistical model developed by Rivier et al. [12] on the basis of merged MERIS/MODIS images for the period 2007-2009 in the English Channel. In this model, the near-surface SSC is expressed as a function of site-specific explanatory variables, such as tides, wind-generated surface-gravity wave amplitudes and Chl-a concentrations, thus integrating the variability of resuspension events. This model approaches, in particular, the daily general patterns of near-surface SSC distribution in the English Channel, including: (1) the horizontal gradients of concentrations in the nearshore regions; and (2) the formation of a turbid area around the Isle of Wight (Figure 2). 


\subsubsection{Parameterizations of the Sediment Transport Module}

The settling velocity and critical shear stress of grain-size classes $i$, with $i \in\left[2, N_{p}\right]$, are parameterized according to the formulations of Soulsby [32] and Soulsby and Whitehouse [33], respectively. For the finest grain-size class with the diameter $d_{1}$, these parameters may, however, be affected by seasonal modulations in relation to biological activity or thermal stratification effects. The presence of sticky organic molecules resulting from the degradation of algae and plankton may thus trigger the seasonality of flocculation, increasing the settling velocity of the finest suspended particles in summer and decreasing it, with the easier break-up of suspended flocs, in winter [34]. Biostabilization processes can also affect the cohesiveness of muddy bottom sediments, resulting in higher critical shear stress in summer than in winter [35]. The development of a thermocline may finally influence near-surface concentrations, inhibiting the transport of turbulence from the bottom to the surface layer [13,36]. Following Gourgue et al.'s [37] formulations and the suggestions of Bowers [36] and Ellis et al. [38], these likely seasonal modulations are approximated here, in a very simplified and rough manner, by a sinusoidal function with a maximum in July and a minimum in January:

$$
\begin{aligned}
& w_{s, 1}^{\bmod }=w_{s, 1}^{\max }\left[\left(\frac{\alpha-1}{2}\right)\left(\cos \left(2 \Pi \frac{t_{\text {days }}}{T}\right)+1\right)+1\right] \\
& \tau_{c r, 1}^{\bmod }=\tau_{c r, 1}^{\max }\left[\left(\frac{\beta-1}{2}\right)\left(\cos \left(2 \Pi \frac{t_{\text {days }}}{T}\right)+1\right)+1\right]
\end{aligned}
$$

where $T$ is the number of days in the year considered and $t_{\text {days }}$ corresponds to the day of the year. $w_{s, 1}^{\bmod }$ and $\tau_{c r, 1}^{\text {mod }}$ are thus oscillating between maximum values of $w_{s, 1}^{\max }$ and $\tau_{c r, 1}^{\max }$ in summer and minimum values of $\alpha w_{s, 1}^{\max }$ and $\beta \tau_{c r, 1}^{\max }$ in winter. These parameters are chosen to vary around the settling velocity and critical shear stress adopted for the finest particles when seasonal modulation is disregarded: $w_{s, 1}=0.36 \mathrm{~mm} \mathrm{~s}^{-1}$ and $\tau_{c r, 1}=0.08 \mathrm{~N} \mathrm{~m}^{-2}$. The following values are finally adopted: $w_{s, 1}^{\max }=0.6 \mathrm{~mm} \mathrm{~s}^{-1}, \tau_{c r, 1}^{\max }=0.2 \mathrm{~N} \mathrm{~m}^{-2}, \alpha=1 / 6$ and $\beta=1 / 6$.

\subsection{Setup}

The geographical domain for full computation of hydrodynamic and sediment transport extends in longitude from $3.300^{\circ} \mathrm{W}-3.000^{\circ} \mathrm{E}$ and in latitude from $48.410^{\circ} \mathrm{N}-51.000^{\circ} \mathrm{N}$ (Figure 1). It is discretized with a spacing of $3 \mathrm{~km}$ and 11 uniform vertical $\sigma$-grid cells. Time steps for the external and internal modes are 30 and $300 \mathrm{~s}$, respectively. This inner computational domain is extended to a larger outer domain from $4.000^{\circ} \mathrm{W}-4.700^{\circ} \mathrm{E}$ and $48.400^{\circ} \mathrm{N}-52.850^{\circ} \mathrm{N}$ in order to achieve more suitable open boundary conditions [8].

The model is driven by the tidal free-surface elevation recomposed from the dominant ten harmonic constituents of the TPXO.6 (TOPEX/Poseidon) database [39]. Wind speeds at $10 \mathrm{~m}$ above the free-surface are provided by the meteorological model ALADIN (Aire Limité, Adaptation Dynamique, Développement International, Météo-France). Wave parameters are finally given by regional Wavewatch III simulations on the northwestern continental shelf (Ifremer, Fabrice Ardhuin). Data are interpolated at each grid node and each time step of the ROMS barotropic mode. 
Previous studies $[8,10]$ have shown that the contribution of bottom sediments to the total SSC was negligible for diameters over $500 \mu \mathrm{m}$. Suspended sediment transport is thus computed for the four grain size classes of silts $\left(d_{1}=25 \mu \mathrm{m}\right)$, very fine sands $\left(d_{2}=75 \quad \mu \mathrm{m}\right)$, fine sands $\left(d_{3}=150 \quad \mu \mathrm{m}\right)$ and medium sands $\left(d_{4}=350 \mu \mathrm{m}\right)$. Suspended transport of coarse sands, which may be neglected in the near-surface SSC, is considered here, as it influences the evolution of bottom grain-size distributions and, consequently, the availability of the finest bed sediments. The sediment bed is initialized following Warner's [18,19] parameterizations with 10 vertical levels where the top 6 layers are $0.01 \mathrm{~m}$ thick and the bottom $40.10 \mathrm{~m}$ thick. All layers have a porosity of 0.36 and, initially, the same grain-size distribution taken to be equal to the distribution in the surface layer. This initial grain-size distribution is determined at the computational grid nodes of the inner domain by applying the interpolation method proposed by Leprêtre et al. [40] to a series of 2318 bottom sediment samples collected in the framework of the RCP (Recherche Coopérative sur Programme) 378 Benthos de la Manche program [41]. According to the AFNOR (Association Française de NORmalisation) sieve analysis performed on bottom samples, the interpolated grain-size distribution is discretized into 10 classes ranging from $50 \mu \mathrm{m}$ to $2 \mathrm{~cm}$, supplemented by a virtual class between $5.5 \mathrm{~cm}$ and $50 \mathrm{~cm}$ to account for boulders and rock outcrops. The computed map of median sieve diameter $D_{50}$ (Figure 3) reproduces sediment patterns established by sedimentologists fairly well [42,43], with very fine sands, silts and muddy sediments in bays and estuaries (e.g., Lyme Bay, Bay of Seine) and pebbles in the Dover Strait, off the "Pays de Caux" and over an extensive zone in the Central Channel between the Isle of Wight and the Cotentin Peninsula. Whereas the bottom roughness parameter is initialized with the interpolated grain-size distributions in the inner domain $\left(z_{0}=D_{50} / 12\right)$, it is set to a constant value of $z_{0}=0.0035 \mathrm{~m}$ in the outer domain [44].

The model is run during the two years 2007 and 2008 characterized by the highest disponibility of cloud-free satellite data. The year 2007 is considered as an initialization period. The sensitivity of model predictions to SSC OBC sources is investigated with four numerical experiments titled A to D in which inputs at the western and northern boundaries are successively modified (Table 1, Figure 4). Simulations integrate input concentrations of fine sediments whose diameter is taken to be equal to the finest grain-size class considered, $d_{1}=25 \mu \mathrm{m}$. Concentrations in the water column are derived from near-surface data assuming uniform vertical profiles. A fifth experiment, titled E, is conducted, integrating modified versions of the settling velocity and the critical shear stress. Numerical experiments are compared with the following parameter:

$$
\operatorname{DIFF}_{k 1-k 2}=\text { MABS }_{k 1}-\text { MABS }_{k 2}
$$

where $\operatorname{MABS}_{k}(k \in[k 1, k 2])$ is the average of the absolute differences between observed $\left(C^{s a t}\right)$ and predicted from case $k\left(C^{\text {mod,k}}\right)$ near-surface concentrations:

$$
\operatorname{MABS}_{k}=\frac{1}{N} \sum_{i=1}^{i=N}\left|C_{i}^{s a t .}-C_{i}^{\text {mod., } k}\right| .
$$

$k 1$ and $k 2$ refer to the two configurations compared $(k 1 \in[A, \ldots E] ; k 2 \in[A, \ldots E]) . N$ is alternately the number of available remote sensing data in the inner computational domain or in the time series considered, whether the analysis focuses on the spatial or temporal variabilities of numerical predictions. Positive values of $\mathrm{DIFF}_{k 1-k 2}$ denote, on average, a better estimation of the observed concentrations 
with the numerical experiment $k 2$ than $k 1$. Additional statistical parameters are considered, like the scatter index:

$$
\mathrm{si}=\frac{\mathrm{rmse}}{(\bar{X} \bar{Y})^{1 / 2}}
$$

with rmse the root mean square error:

$$
\text { rmse }=\left[\frac{1}{N} \sum_{i=1}^{i=N}\left(y_{i}-x_{i}\right)^{2}\right]^{1 / 2}
$$

and the index agreement:

$$
\text { re }=1-\frac{\sum_{i=1}^{i=N}\left|y_{i}-x_{i}\right|^{2}}{\sum_{i=1}^{i=N}\left(\left|y_{i}-\bar{X}\right|+\left|x_{i}-\bar{X}\right|\right)^{2}}
$$

where $\left(x_{i}\right)$ and $\left(y_{i}\right)$ represent the two sets of observed and simulated data, respectively, and $\bar{X}$ and $\bar{Y}$ are the average of observations $\left(x_{i}\right)$ and predictions $\left(y_{i}\right)$ in the series considered. The index of agreement varies between 0 and 1 . It equals unity for perfect agreement.

Table 1. List of numerical experiments.

\begin{tabular}{ccc}
\hline $\begin{array}{c}\text { Numerical } \\
\text { Experiments }\end{array}$ & $\begin{array}{c}\text { SSC OBCs } \\
\text { Sources }\end{array}$ & $\begin{array}{c}\text { Parameterizations } \\
\text { of } w_{s, 1} \text { and } \tau_{c r, 1}\end{array}$ \\
\hline A & No inputs & Not modulated [32,33] \\
B & MODIS monthly climatology [1] & Not modulated [32,33] \\
C & Daily SSC from statistical model [12] & Not modulated [32,33] \\
D & Monthly averaged SSC from statistical model [12] & Not modulated [32,33] \\
E & Daily SSC from statistical model [12] & Modulated [37] \\
\hline
\end{tabular}
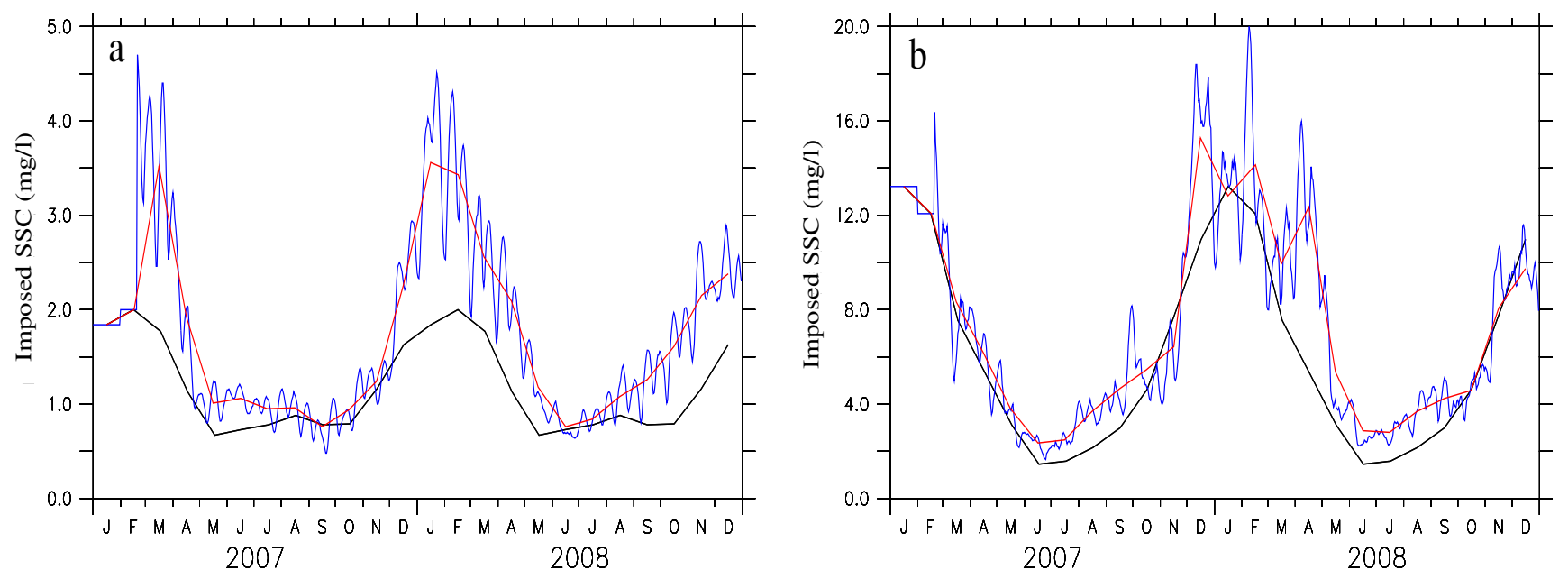

Figure 4. Time series of imposed near-surface SSC in Configurations (black line) B, (blue line) $\mathrm{C}$ and (red line) D averaged along the (a) western and (b) northern boundaries of the outer computational domain. 


\section{Results and Discussion}

\subsection{Comparison with Observations}

Predictions of tidal free-surface elevation have been assessed against in situ observations in a series of harbors of the English BODC (British Oceanographic Data Centre) and French SONEL (Système d'Observation du Niveau des Eaux Littorales) networks. Differences are globally restricted to less than five percent of spring-neap tidal elevations [45]. An overall good agreement is also obtained between numerical results and cartography of spring tidal ranges and currents established by the SHOM (Service Hydrographique et Océanographique de la Marine) [46] in the English Channel. These results confirm the model's capability to reproduce large-scale tidal patterns.

\subsubsection{Local Evaluation}

The performances of the sediment transport module are evaluated for the reference Configuration A. Comparisons between predictions and remote sensing data are conducted locally at four points, titled M1-M4 (Figures 1 and 5). According to Rivier et al. [12], these locations are characterized by contrasting spring-neap tidal modulations of observed near-surface SSC. The strongest hydrodynamic conditions are obtained at Points M1 and M2 with spring tidal currents exceeding $2.5 \mathrm{~m} \mathrm{~s}^{-1}$ and moderate to strong expositions to North Atlantic incoming waves. The resulting near-surface SSC is characterized by sharp spring-neap tidal modulations, particularly noticeable at Point M2 with values evolving from $6 \mathrm{mgl}^{-1}$ in spring tide to $2 \mathrm{mgl}^{-1}$ in neap tide. Point M3, located in the turbid area surrounding the Isle of Wight, exhibits the strongest near-surface SSC with yearly-averaged values around 10/15 $\mathrm{mgl}^{-1}$. The last position, M4, in the eastern English Channel is finally characterized by the weakest hydrodynamic conditions with spring tidal currents below $1.5 \mathrm{~m} \mathrm{~s}^{-1}$. The temporal evolution of observed near-surface SSC shows a moderate influence of spring-neap tidal cycles.

The predictions reproduce globally the observed spring-neap tidal modulations of near-surface SSC at the four locations considered (Figure 5). The agreement is particularly noticeable at Point M2, characterized by strong tidal currents. The effects of winter storms appear also in predictions, increasing near-surface SSC up to $20 \mathrm{mg}^{-1}$ at Point M3. Nevertheless, the model in the reference Configuration A has a global tendency to underestimate satellite observations in winter while overestimating in summer. At Point M1, the observed near-surface SSC exceeds, in March, 2008, $8 \mathrm{mg} \mathrm{l}^{-1}$, while the numerical result remains below $4 \mathrm{mg} \mathrm{l}^{-1}$. At this location, the scatter index between predictions and observations reaches 2.4, contrasting with the estimations at Points M2-M4 (Figure 6). Satellite data at Point M4 appear finally to include unrealistic values in March, 2008, likely attributed to the tendency of the remote sensing algorithm to overestimate the highest near-surface concentrations [1].

\subsubsection{Synoptic Evaluation}

Synoptic comparisons between predictions and satellite images are conducted to give further insights into the ROMS performances at the scale of the inner computational domain (Figures 7 and 8). Six rough satellite images are selected considering different tidal and waves hydrodynamic regimes. The comparison is first established in moderate wave conditions (average significant wave height below 
$1.5 \mathrm{~m}$ ) for spring (6 May 2008), mean (23 July 2008) and neap (11 October 2008) tides (Figure 7). It is then set up in strong hydrodynamic regimes characterized by stormy waves with averaged significant wave height over $3 \mathrm{~m}$ in spring (21 March 2008) and mean (11 November 2008) tides (Figure 8). The last situation considers the conjunction of a state of rest after a stormy wave and spring tide (11 February 2008).
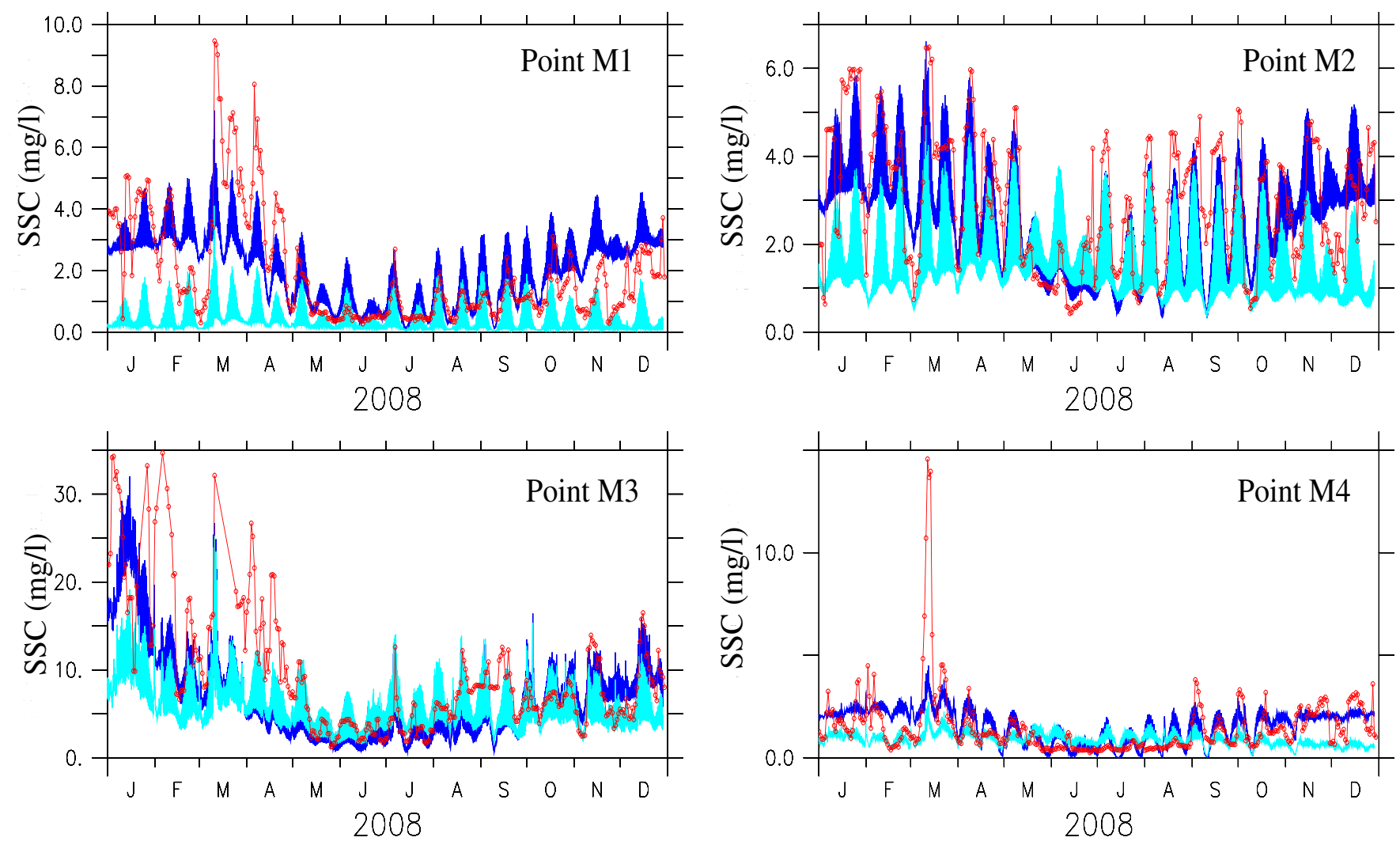

Figure 5. Time series of near-surface concentrations (red line) observed and predicted in Configurations (light blue line) A and (blue line) E at Points M1-M4 in 2008.
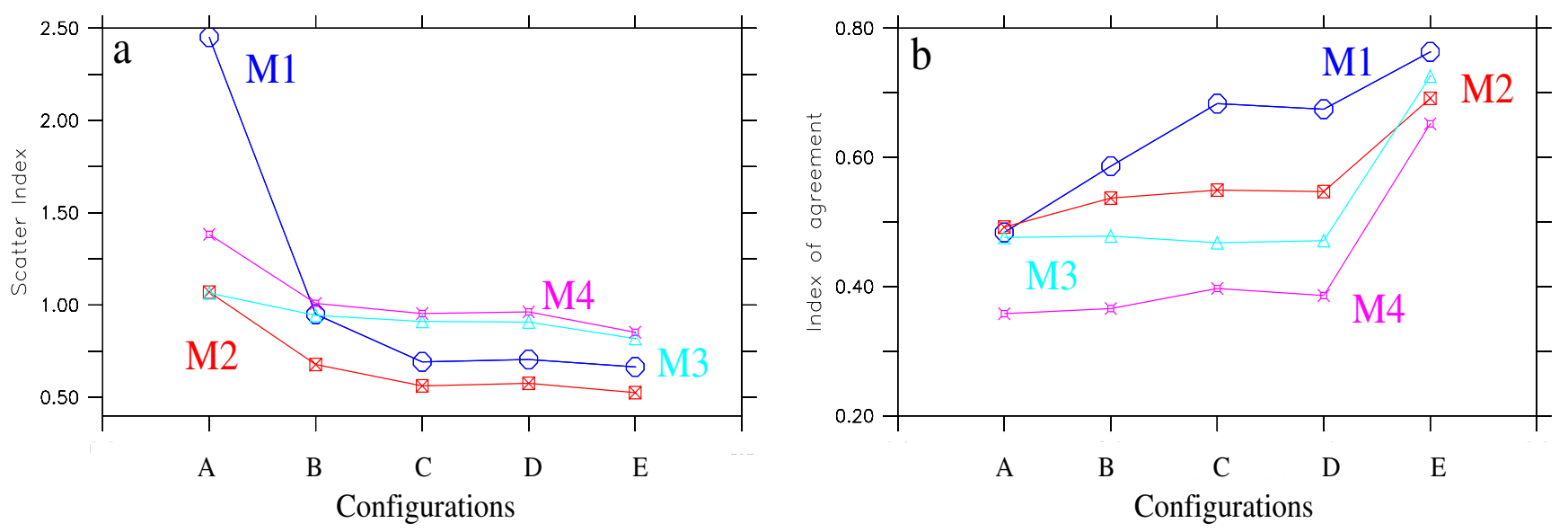

Figure 6. (a) Scatter index and (b) index of agreement in predictions of near-surface SSC at Points M1, M2, M3 and M4 in Configurations A-E. 

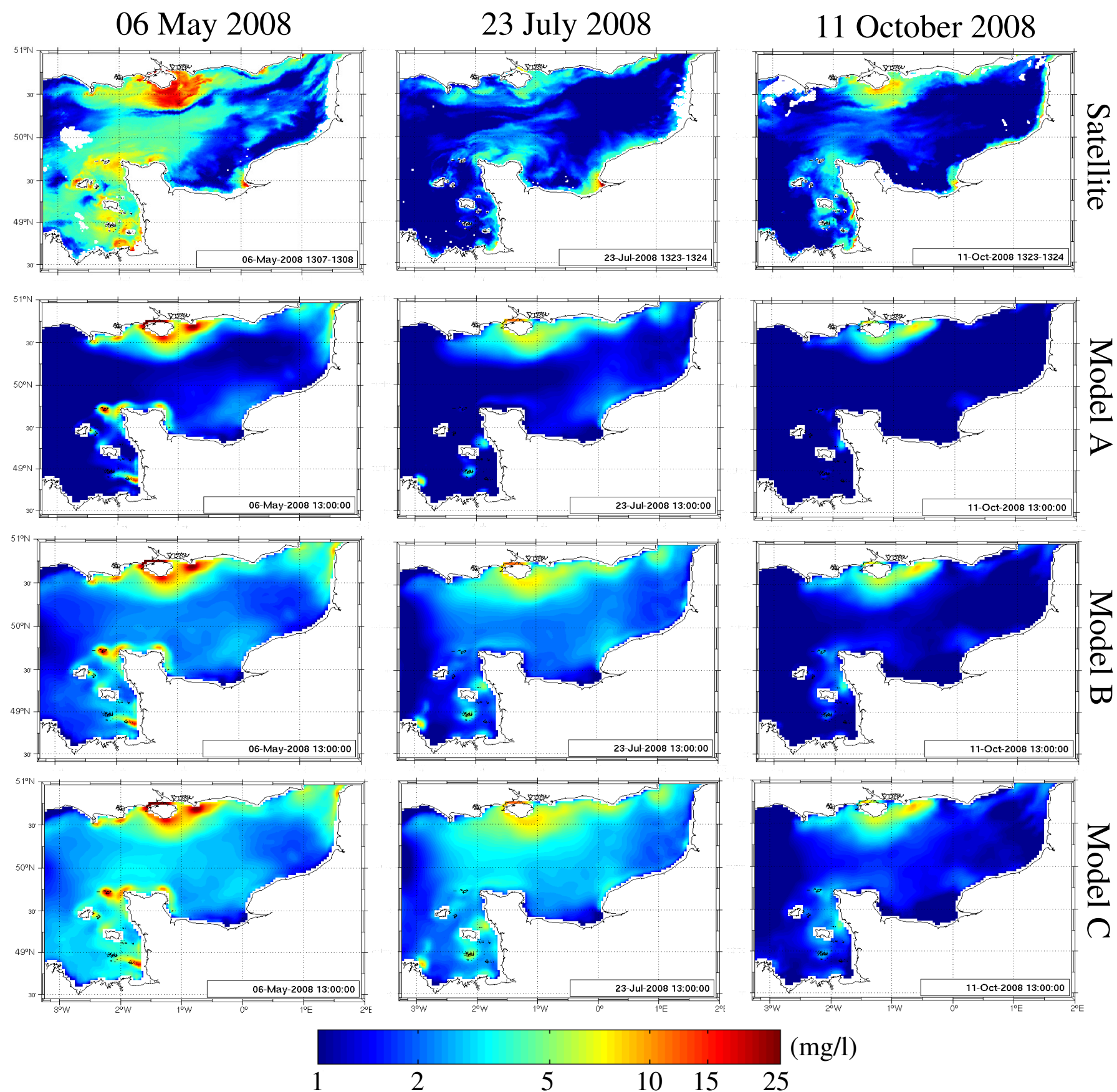

Figure 7. Near-surface SSC observed and computed in Configurations A, B and C for moderate waves conditions and spring (6 May 2008, MODIS), mean (23 July 2008, MODIS) and neap (11 October 2008, MODIS) tides.

An overall agreement is obtained between remote-sensing data and predictions of major near-surface SSC features in the English Channel. The model reproduces the horizontal near-surface SSC gradient of the Wight-Cotentin section characterized by: (1) an English coastal zone with the highest concentrations; (2) a French coastal zone with intermediate values; and (3) the offshore (central) waters of the Channel with the lowest SSC [5]. This spatial distribution is partly associated with the formation of a highly turbid area surrounding the Isle of Wight. Predictions reproduce this prominent feature fairly well, in particular: (1) the asymmetry of this turbid area characterized by larger eastern stretching; and (2) the variation of near-surface SSC in relation to tidal hydrodynamic regimes. In this area, the averaged 
concentrations are thus increasing from $5 \mathrm{mg} \mathrm{l}^{-1}$ in neap tide to more than $15 \mathrm{mg} \mathrm{l}^{-1}$ in spring following satellite observations. The model approaches also secondary features identified locally in the vicinity of protruding headlands and isles along English and French coastlines (e.g., off Portland and Eastbourne or around the Cotentin Peninsula, the Channel Islands Gulf and the Pays-de-Caux). Observed SSC are however strongly underestimated in offshore central waters during spring tides (11 February, 21 March and 6 May 2008).

11 February 2008
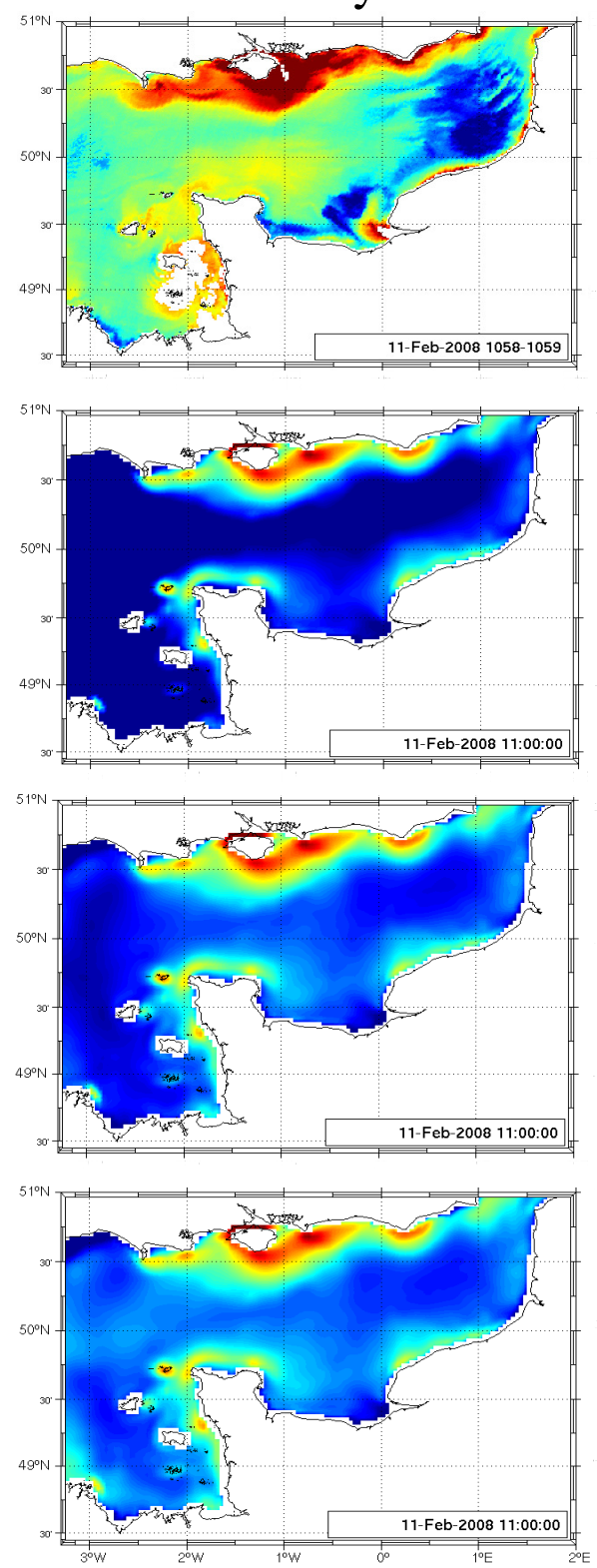

21 March 2008
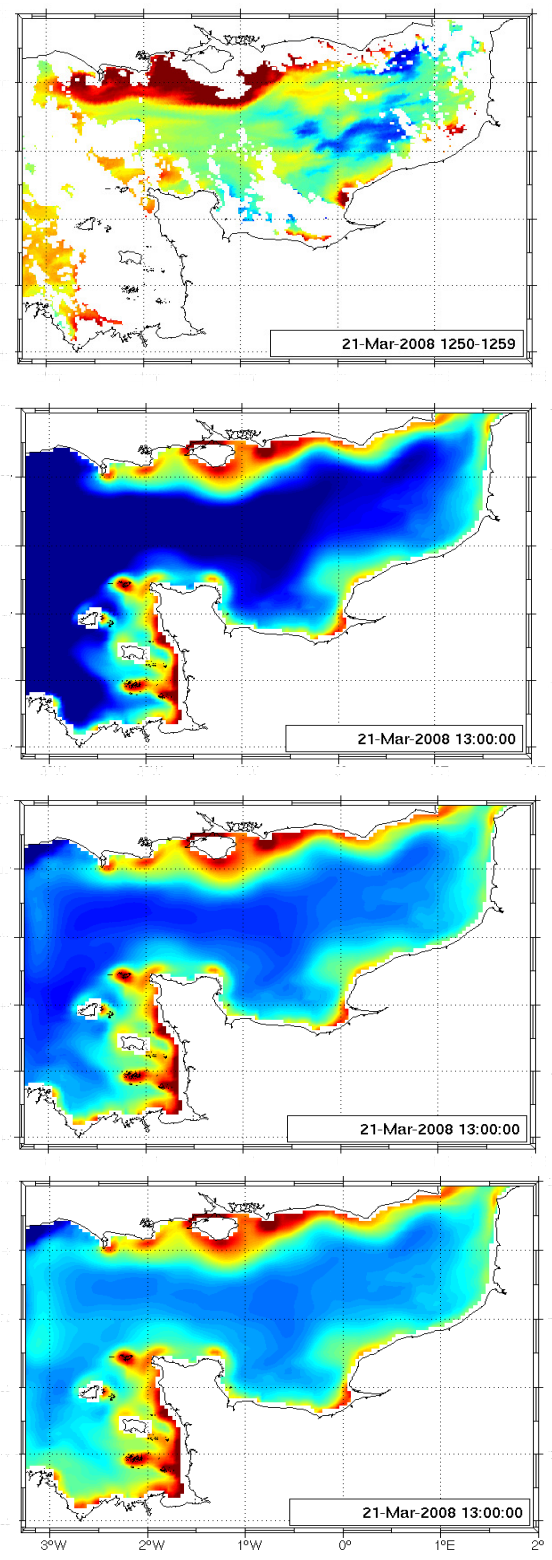

11 November 2008
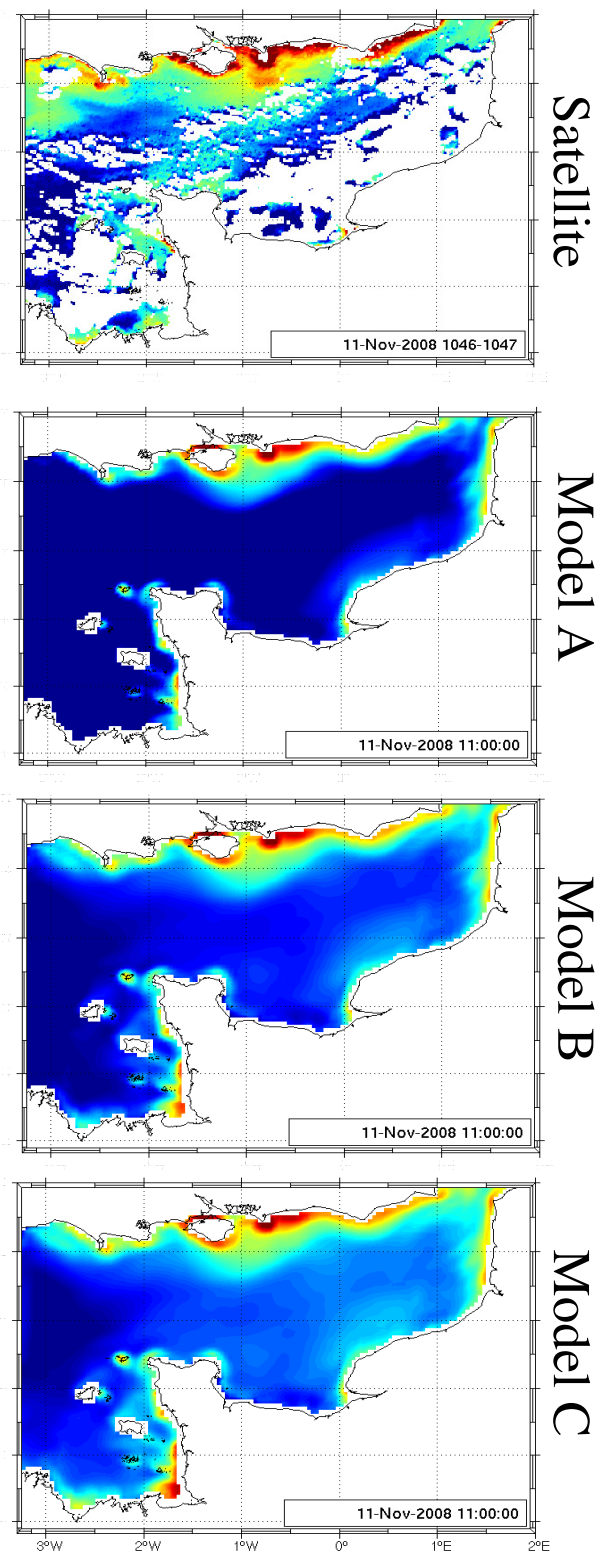

$(\mathrm{mg} / \mathrm{l})$

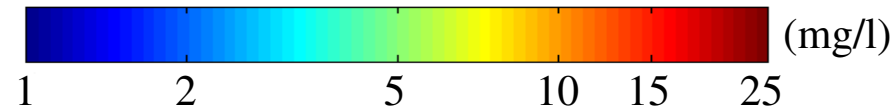

Figure 8. Near-surface SSC observed and computed in Configurations A, B and C for stormy wave conditions and spring (11 February and 21 March 2008, MERIS and MODIS) and mean (11 November 2008, MERIS) tides. 


\subsection{Sensitivity to SSC OBCs}

Differences exhibited in offshore central waters suggest remote advective and diffusive transport of fine suspended sediments from the outer open boundaries. A sensitivity study is conducted to investigate differences in the predictions of near-surface SSC for a series of inputs of concentrations at the sea boundaries.

The integration of SSC inputs improves the predictions at the four locations M1 to M4 (Figure 6). The scatter index at Point M1 decreases thus from 2.45 (Configuration A) to 0.95 by introducing OBCs' climatologies (Configuration B). Refined daily SSC inputs issued from the statistical model (Configuration $C$ ) improve also numerical results. At Point M1, the index of agreement between predictions and satellite observations is thus increasing from 0.58 (Configuration $\mathrm{B}$ ) to 0.68 (Configuration C). Slight differences are furthermore obtained by decreasing the temporal resolution of imposed concentrations (Configuration D). Point M3, located in the high turbid area surrounding the Isle of Wight, appears finally barely sensitive to SSC inputs. This low sensitivity may be explained by dominant local resuspensions together with complex recirculations, likely responsible for trapping of suspended particles. In the English Channel, tidal residual suspended load transports are thus characterized by a central divergence zone in the form of a "Y" shape ending with two branches on both sides of the Isle of Wight [8]. The intermediate region between the two northern branches is characterized by complex sediment transport pathways with two prominent gyres. As exhibited by Menesguen and Gohin [47], these features are likely responsible for trapping suspended particles coming from two major sources of silts: (1) Lyme Bay; and (2) the western approach of the Solent (Figure 3).

At the scale of the computational domain, SSC inputs are leading to a prominent increase of near-surface concentrations in the central waters for the highest hydrodynamic conditions (6 May, 11 February and 21 March 2008) (Figures 7 and 8). This effect is particularly noticeable during spring tides of 6 May 2008. The predictions in Configuration $\mathrm{C}$ are thus increasing up to $4 \mathrm{mg} \mathrm{l}^{-1}$ over the gravel areas of the Wight-Cotentin section approaching the observed near-surface concentrations of $5 \mathrm{mg}^{-1}$. Whereas a non-negligible contribution originates from local resuspensions of silts in bays, estuaries and isolated coastal deposits on both sides of the headlands [8], concentrations in offshore waters appear mainly influenced by SSC inputs at the sea boundaries. This result confirms the importance of the advection of fine-grained suspended sediments in the central waters of the English Channel as exhibited by Jones et al. [49] or Velegrakis et al. [5]. The general circulation of suspended particles in offshore waters has thus been identified by Salomon and Breton [48] as a central "river" flowing from the North Atlantic Ocean to the North Sea. This central "river" is however characterized by coastal re-circulations, induced by headlands or islands, liable to release or trap suspended particles as exhibited for the turbidity area surrounding the Isle of Wight [47]. SSC inputs are thus influencing the predictions of nearshore features, improving the spatial extension of these turbid coastal areas.

Modeling performances are evaluated, further displaying the evolutions of spatially-averaged differences $\mathrm{DIFF}_{A-B}$ and $\mathrm{DIFF}_{A-C}$ for days with an index coverage of satellite data over $50 \%$ in the computational domain. The highest value between raw MODIS and MERIS images is retained (Figure 9). Positive values exhibit improved estimations of concentrations with Configurations B and C, respectively. SSC inputs appear significant from January to May and from September to December. 
During these periods, the major improvements of numerical predictions are obtained in areas of the highest tidal currents amplitude of the Channel Islands Gulf and the Cotentin Peninsula in relation to significant transport of suspended sediments (Figure 10). Whereas the influence of prevailing waves on the seabed is restricted to water depths below $30 \mathrm{~m}$ in the English Channel [50], waves may have an indirect effect on suspended transport in offshore waters, increasing SSC inputs at the sea boundaries during storm events. During the intermediate period, between May and September, SSC boundary inflows however increase the spatial-averaged differences, leading to an excess of suspended particles, particularly noticeable in the eastern English Channel (Figures 9 and 10). Nevertheless, refined SSC inputs, integrating the daily variability of hydrodynamic conditions [12] (Configuration C), improve the numerical estimations in the western English Channel in winter and autumn with a maximum value of $\mathrm{DIFF}_{A-C}$ at $2.5 \mathrm{mg} \mathrm{l}^{-1}$ (Figures 9 and 10). The temporal resolution of these realistic SSC inputs finally appears to have a lower impact on near-surface predictions with values of $\mathrm{DIFF}_{C-D}$ below $0.1 \mathrm{mg}^{-1}$. This result confirms the conclusions established at the four locations, M1-M4.
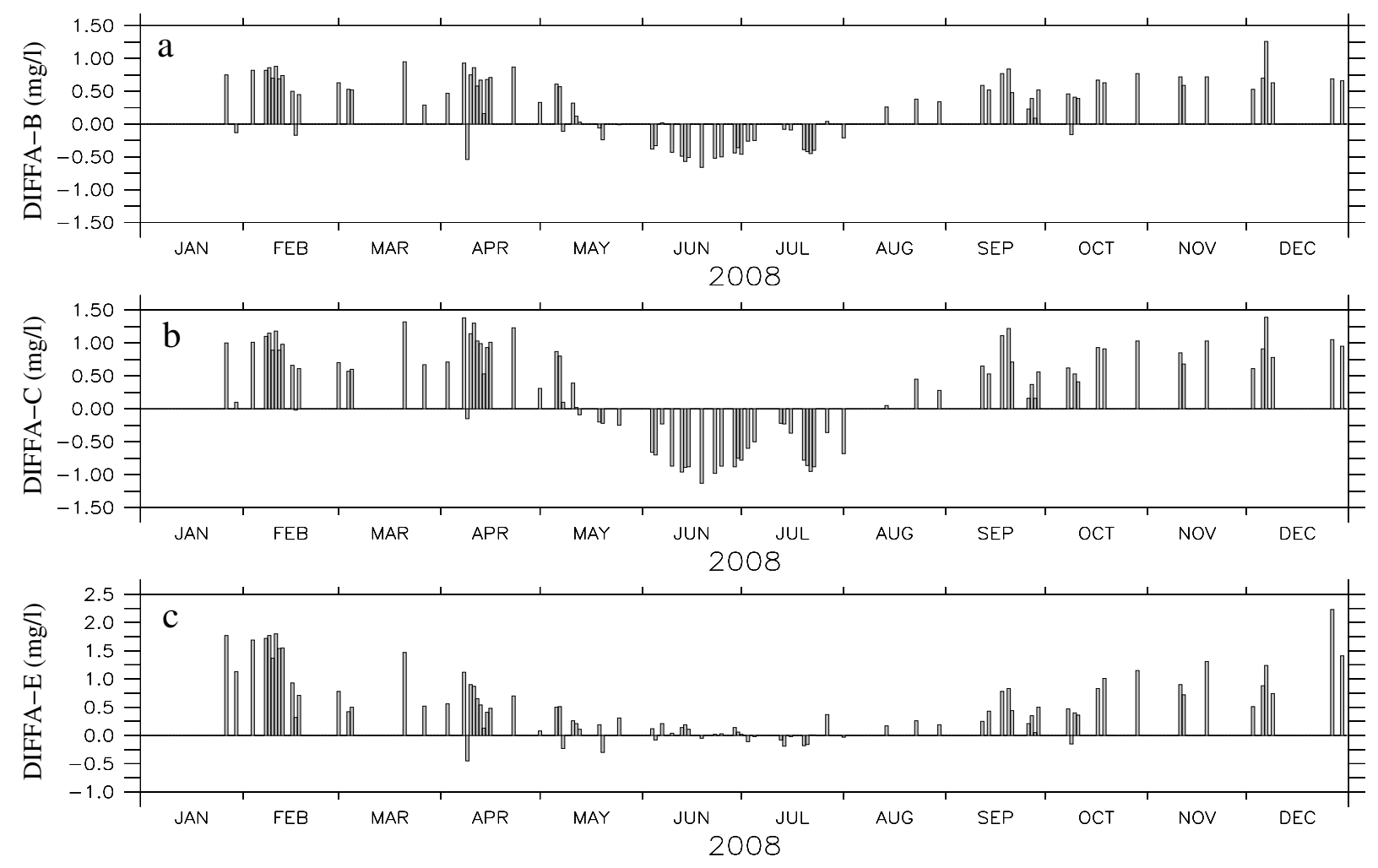

Figure 9. Temporal evolutions of spatially-averaged differences (a) $\operatorname{DIFF}_{A-B}$, (b) $\operatorname{DIFF}_{A-C}$ and (c) DIFF $_{A-E}$. Positive values indicate improved estimations of near-surface SSC with configurations (a) B, (b) C and (c) E, respectively.

\subsection{Seasonal Effects}

These differences may reveal possible seasonal processes neglected in the present modeling, like the effects of biological activity (e.g., flocculation break-up, biostabilization) [5] or thermal stratification and its likely consequence on the transport of turbulence from the bottom to the surface layer [13]. Simple 
parameterizations of the settling velocity and the critical shear stress adopted here enable a preliminary estimation of these effects on suspended sediment transport in the English Channel.
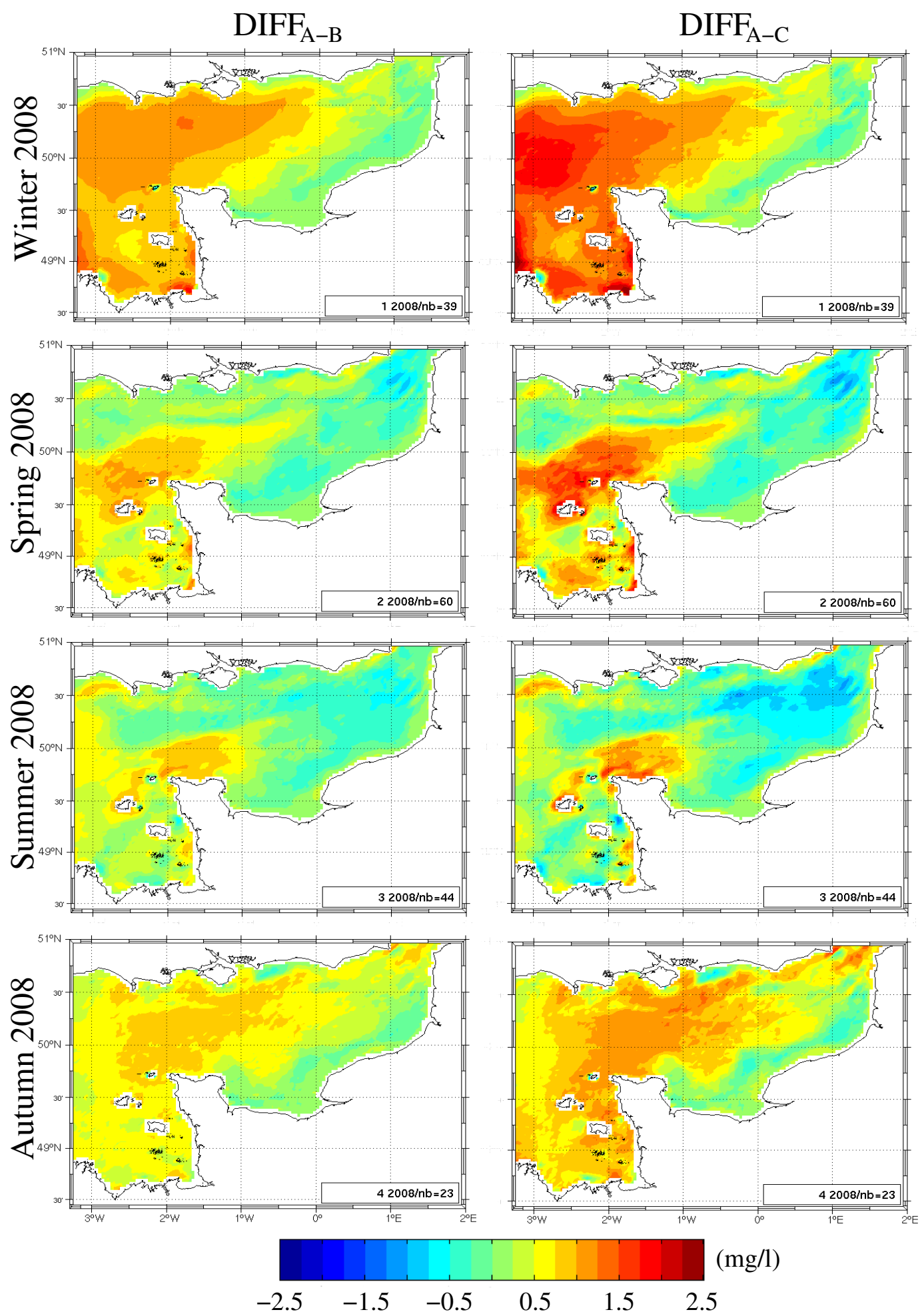

Figure 10. Differences in the estimation of observed near-surface SSC between Configurations (left) $\mathrm{A}$ and $\mathrm{B}\left(\mathrm{DIFF}_{A-B}\right)$ and (right) $\mathrm{A}$ and $\mathrm{C}\left(\mathrm{DIFF}_{A-C}\right)$ in winter, spring, summer and autumn 2008. Positive values show improved estimations with Configurations $\mathrm{B}$ and $\mathrm{C}$, respectively. 
Seasonal modulations (Configuration E) substantially improve numerical results at Points M1-M4 decreasing near-surface concentrations in spring and summer 2008, while increasing predicted levels in winter and autumn (Figure 5). The index of agreement is thus increasing to values over 0.65 at the four points considered (Figure 6).

The comparisons between predictions of (1) raw satellite data (Figure 11) and (2) observed MODIS monthly climatologies (Figure 12) confirm the model's improvements obtained by introducing seasonal modulations of the settling velocity and the critical shear stress. The simple modulations tested here are thus found to have a major effect around the Isle of Wight and in offshore central waters, avoiding unrealistic predicted levels in summer and spring. Improvements are exhibited by comparing the total histogram area in Figure 9. The total area of $\operatorname{DIFF}_{A-E}$ reaches thus $46.6 \mathrm{mg} \mathrm{l}^{-1}$, while it is restricted to $27.2 \mathrm{mg} \mathrm{l}^{-1}$ for $\mathrm{DIFF}_{A-C}$.

The formulations adopted here consider a spatially-uniform modulation of the settling velocity and the critical shear stress, disregarding the likely heterogeneity and variability of the processes involved. Nevertheless, the results obtained here suggest seasonal modulations of these two key parameters. We have also to notice that, in return, the satellite SSC should be seasonally modified to take into account the varying inherent optical properties of the particles along the year. Further investigations are naturally required to clearly establish these modulations on the basis of more sophisticated models [38,51], explicitly integrating the influences of water temperature and salinity, organic matter concentrations or turbulent variables.
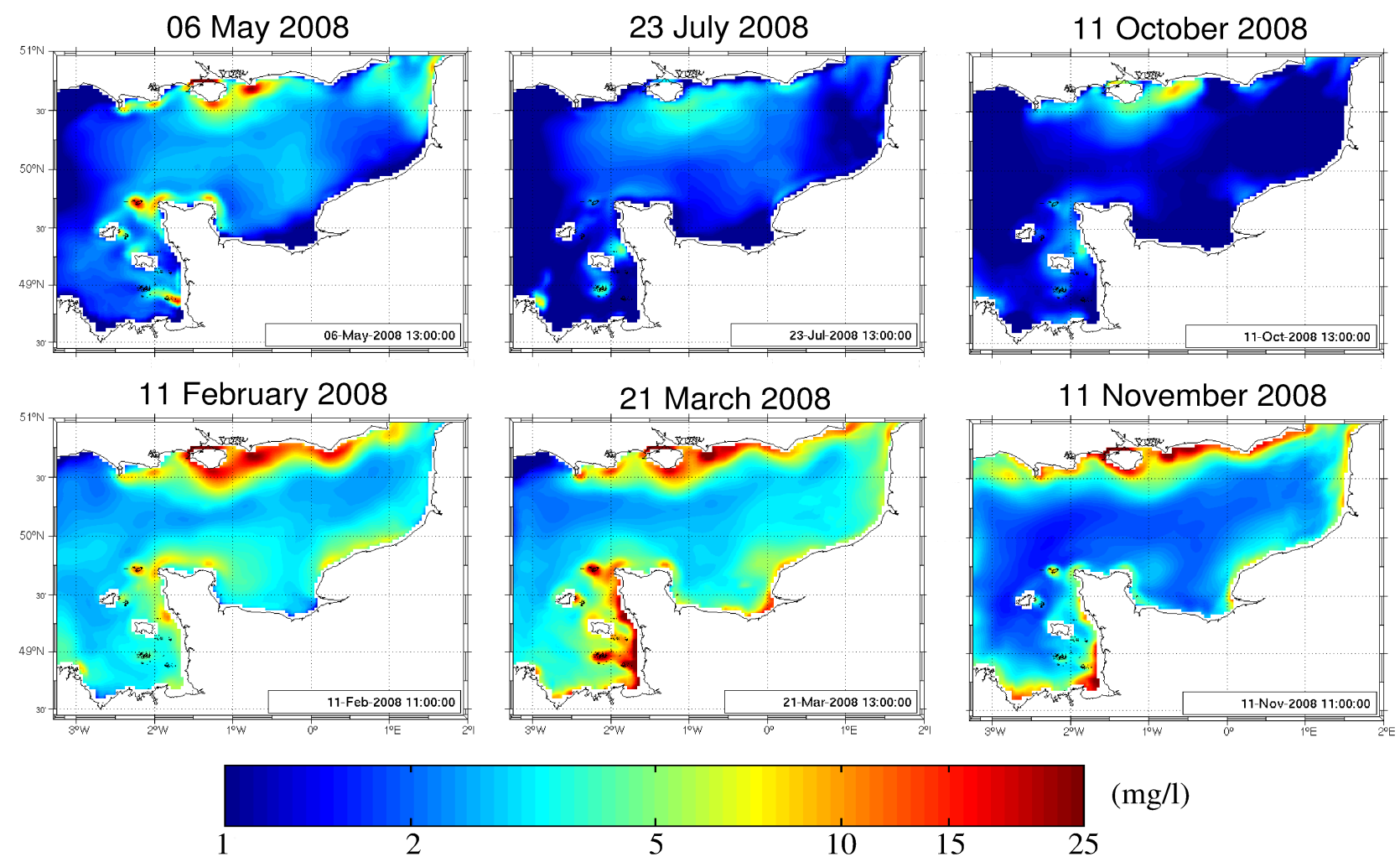

Figure 11. Near-surface SSC computed in Configuration E on 6 May, 23 July, 11 October, 11 February, 21 March and 11 November 2008. 


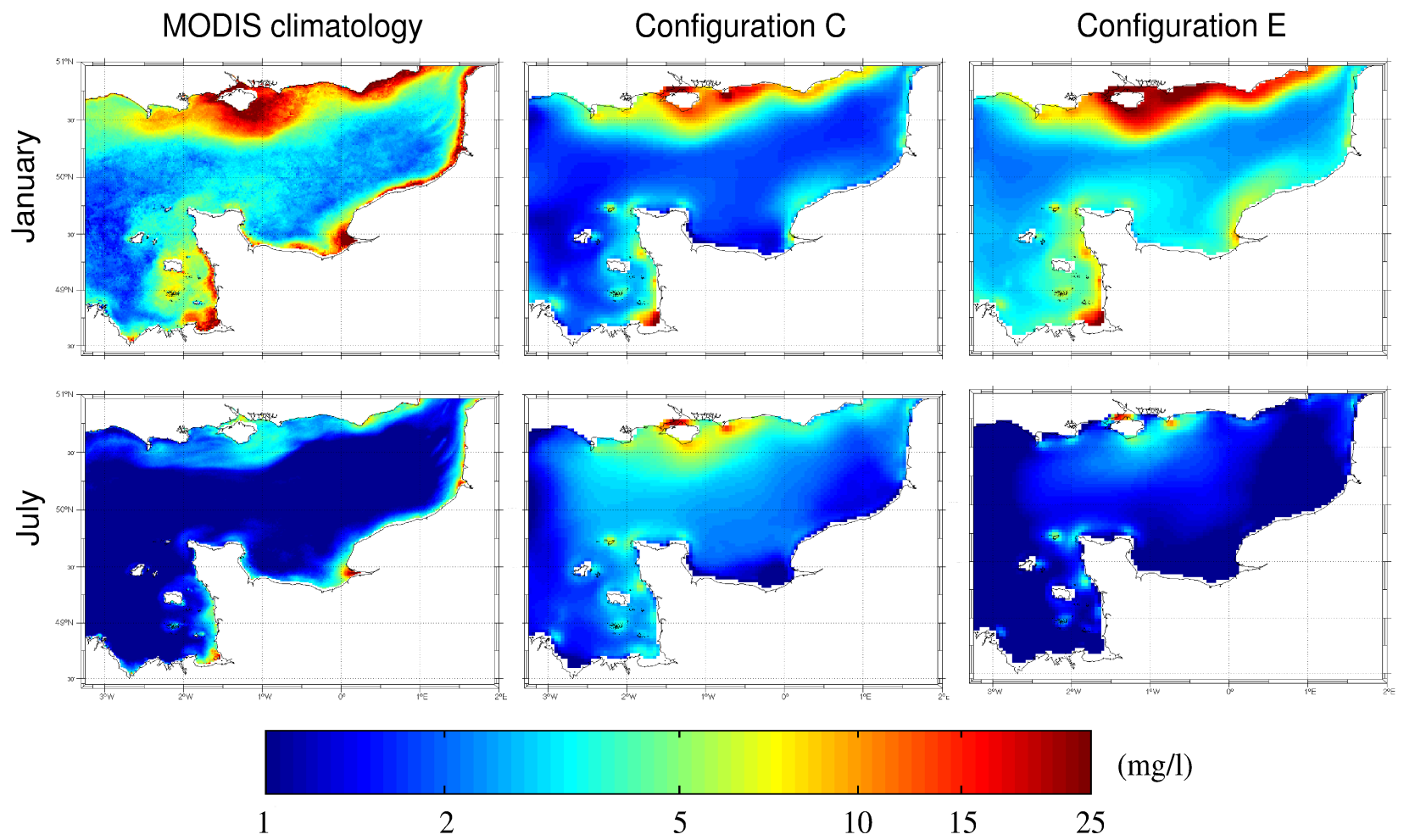

Figure 12. Monthly averaged near-surface SSC (left) issued from MODIS climatology and predicted in Configurations (center) C and (right) E in January and July, 2008.

\section{Conclusions}

A fully-3D multicomponent hydro-sedimentary modeling system based on ROMS has been implemented in the English Channel integrating major hydrodynamic forcings of tide and waves and realistic bottom sediment granulometric distributions. Numerical predictions have been compared with satellite images of near-surface SSC in order to analyze the performances of the modeling system obtained with a new set of daily OBCs and simple parameterizations of the suspended sediment transport module. The main outcomes of the present study are the following.

1. Predictions successfully approach the distribution of near-surface suspended concentrations captured by the satellite. The present simulation reproduces especially the highly turbid area surrounding the Isle of Wight and its variability in different tidal and wave regimes. These results confirm the importance of encompassing the large panel of hydrodynamic conditions and bottom sedimentary areas for near-surface SSC modeling in the English Channel.

2. Sensitivity studies confirm the importance of the advection of fine-grained suspended sediments in the central waters of the English Channel. Predictions exhibit furthermore the benefits of integrating refined estimations of concentration inputs along the sea boundaries in a region characterized by a west-eastern circulation of suspended particles. The slight differences between daily and monthly OBCs issued from the statistical model advocate furthermore for the implementation of monthly SSC forcings integrating the inter-annual variability of resuspensions events. 
3. The modified formulations of the settling velocity and the critical shear stress finally appear to improve the numerical predictions of near-surface concentrations in the English Channel. Whereas further investigations are required to clearly establish the importance of the associated processes (aggregation, biostabilization, thermal stratification, etc.), these results suggest possible seasonal modulations of two keys parameters influencing suspended sediment transport in the area considered.

The present study thus provides interesting insights into improvements of near-surface SSC modeling in the English Channel that are widely adaptable to other hydro-sedimentary modeling systems. This research will naturally benefit from extended comparison of numerical predictions with in situ observations in the most turbid areas during storm events. Another prospect of this research will consist of incorporating fluxes of fresh waters and sediment through rivers' boundaries, particularly those from the Seine and the Thames, thus extending the computational area for suspended sediment transport.

\section{Acknowledgments}

The authors are particularly grateful to the MyOcean (European Commission) project [17] and the space agencies for providing ocean color data from MODIS (NASA) and MERIS (ESA), as well as to the IOWAGA (Integrated Ocean WAves for Geophysical and other Applications) project (European Commission) [52] for supplying wave data. Wind field data of the meteorological model ALADIN were provided by Météo-France. Numerical simulations were performed at the computer facilities CAPARMOR (CAlcul PARallèlle Mutualisé pour l'Océanographie et la Recherche). The present paper is a contribution to the research program FLUSED (FLUx SEDimentaires) of the Cerema (Centre d'études et d'expertise sur les risques, l'environnement, la mobilité et l'aménagement, Laboratory of Coastal Engineering and Environment) [53].

\section{Author Contributions}

Nicolas Guillou supervised the model runs, performed the data analysis and wrote the manuscript. Aurélie Rivier completed the model implementation and performed the comparisons of the numerical results with the satellite-retrieved data. Francis Gohin contributed to the satellite data analysis. Georges Chapalain provided his expertise on suspended sediment transport in the English Channel.

\section{Conflicts of Interest}

The authors declare no conflict of interest.

\section{References}

1. Gohin, F. Annual cycle of chlorophyll- $a$, non-algal suspended particulate matter and turbidity observed from space and in-situ in coastal waters. Ocean Sci. 2011, 7, 705-732.

2. Pingree, R.D.; Griffiths, D.K. Sand transport paths around the British Isles resulting from $\mathrm{M}_{2}$ and $\mathrm{M}_{4}$ tidal interactions. J. Mar. Biol. Assoc. UK 1979, 59, 497-513. 
3. Kenyon, N.H.; Stride, A.H. The tide-swept continental shelf sediments between the Shetland Isles and France. Sedimentology 1970, 14, 159-173.

4. Grochowski, N.T.L.; Collins, M.B.; Boxall, S.R.; Salomon, J.C. Sediment transport predictions for the English Channel, using numerical models. J. Geol. Soc. 1993, 150, 683-695.

5. Velegrakis, A.F.; Michel, D.; Collins, M.B.; Lafite, R.; Oikonomou, E.K.; Dupont, J.P.; Huault, M.F.; Lecouturier, M.; Salomon, J.C.; Bishop, C. Sources, sinks and resuspension of suspended particulate matter in the eastern English Channel. Cont. Shelf Res. 1999, 19, 1933-1957.

6. Lafite, R.; Shimwell, S.; Grochowski, N.; Dupont, J.P.; Nash, L.; Salomon, J.C.; Cabioch, L.; Collins, M.; Gao, S. Suspended particulate matter fluxes through the Straits of Dover, English Channel: Observations and modelling. Oceanol. Acta 2000, 23, 687-699.

7. Guillou, N.; Chapalain, G.; Thais, L. Three-dimensional modeling of tide-induced suspended transport of seabed multicomponent sediments in the eastern English Channel. J. Geophys. Res. 2009, 114, C07025.

8. Guillou, N.; Chapalain, G. Numerical simulation of tide-induced transport of heterogeneous sediments in the English Channel. Cont. Shelf Res. 2010, 30, 806-819.

9. Gerritsen, H.; Vos, R.; der Kaaij, T.V.; Lane, A.; Boon, J. Suspended sediment modelling in a shelf sea (North Sea). Coast. Eng. 2000, 41, 317-352.

10. Guillou, N.; Chapalain, G. Modelling impact of northerly wind-generated waves on sediments resuspensions in the Dover Strait and adjacent waters. Cont. Shelf Res. 2011, 31, 1894-1903.

11. Fettweis, M.; Monbaliu, J.; Baeye, M.; Nechad, B.; van den Eynde, D. Weather and climate induced variability of surface suspended particulate matter concentration in the North Sea and the English Channel. Methods Oceanogr. 2012, 3-4, 25-39.

12. Rivier, A.; Gohin, F.; Bryère, P.; Petus, C.; Guillou, N.; Chapalain, G. Observed vs. predicted variability in non-algal suspended particulate matter concentration in the English Channel in relation to tides and waves. Geo-Mar. Lett. 2012, 32, 139-151.

13. Souza, A.J.; Holt, J.T.; Proctor, R. Modelling SPM on the NW European shelf seas. In Coastal and Shelf Sediment Transport; Balson, P., Collins, M., Eds.; Geological Society: London, UK, 2007; pp. 147-158,

14. Sykes, P.A.; Barcelia, R.M. Assessment and development of a sediment model within an operational system. J. Geophys. Res. 2012, 117, C04036.

15. Gohin, F.; Druon, J.N.; Lampert L. A five channel chlorophyll algorithm applied to SeaWiFS data processed by SeaDAS in coastal waters. Int. J. Remote Sens. 2002, 23, 1639-1661.

16. Gohin, F.; Loyer, S.; Lunven, M.; Labry, C.; Froidefond, J.M.; Delmas, D.; Huret, M.; Herbland, A. Satellite-derived parameters for biological modelling in coastal waters: Illustration over the eastern continental shelf of the Bay of Biscay. Remote Sens. Environ. 2005, 95, 29-46.

17. MyOcean Webpage. Available online: http://www.myocean.eu (accessed on 28 April 2015).

18. Warner, J.C.; Sherwood, C.R.; Signell, R.P.; Harris, C.K.; Arango, H.G. Development of a threedimensional, regional, coupled wave, current, and sediment-transport model. Comput. Geosci. 2008, 34, 1284-1306. 
19. Warner, J.C.; Butman, B.; Dalyander, P.S. Storm-driven sediment transport in Massachussetts Bay. Cont. Shelf Res. 2008, 28, 257-282.

20. Smagorinsky, J. General circulation experiments with the primitive equations, I, the basic experiments. Mon. Weather Rev. 1963, 91, 99-164.

21. Umlauf, L.; Burchard, H. A generic length-scale equation for geophysical turbulence models. J. Mar. Res. 2003, 61, 235-265.

22. Fairall, C.; Bradley, E.; Rogers, D.; Edson, J.; Youngs, G. Bulk parameterization of air-sea fluxes for tropical ocean-global atmosphere coupled-ocean atmosphere response experiment. J. Geophys. Res. 1996, 101, 3747-3764.

23. Soulsby, R.L.; Hamm, L.; Klopman, G.; Myrhaug, D.; Simons, R.R.; Thomas, G.P. Wave-current interaction within and outside the bottom boundary layer. Coast. Eng. 1993, 21, 41-69.

24. Flather, R.A. A tidal model of the northwest european continental shelf. Mémoires Soc. $R$. Sci. Liège 1976, 97, 141-164.

25. Chapman, D.C. Numerical treatment of Cross-Shelf open boundaries in a barotropic coastal ocean model. J. Phys. Oceanogr. 1985, 15, 1060-1075.

26. Haidvogel, D.B.; Arango, H.G.; Hedstrom, K.; Beckman, A.; Malanotte-Rizzoli, P.; Shchepetkin, A.F. Model evaluation experiments in the North Atlantic Basin: simulations in nonlinear terrain-following coordinates. Dyn. Atmos. Oceans 2000, 32, 239-281.

27. Lick, W. Entrainment, deposition and transport of fine-grained sediments in lakes. Hydrobiologia 1982, 91, 31-40.

28. Ariathurai, R.; Arulanandan, K. Erosion rates of cohesive soils. J. Hydraul. Division ASCE 1978, 104, 279-282.

29. Drake, D.E.; Cacchione, D.A. Estimates of the suspended sediment reference concentration $\left(c_{a}\right)$ and resuspension coefficient $\left(\gamma_{0}\right)$ from near-bed observations on the California shelf. Cont. Shelf Res. 1989, 9, 51-64.

30. Blaas, M.; Dong, C.; Marchesiello, P.; McWilliams J.C.; Stolzenbach, K.D. Sediment-transport modeling on Southern Californian shelves: A ROMS case study. Cont. Shelf Res. 2007, 27, 832-853.

31. Harris, C.K.; Wiberg, P.L. Approaches to quantifying long-term continental shelf sediment transport with example from the northern California STRESS mid-shelf site. Cont. Shelf Res. 1997, 17, 1389-1418.

32. Soulsby, R. Dynamics of Marine Sands; Wallingford, H.R., Ed.; Thomas Telford Publications: London, UK, 1997; p. 249.

33. Soulsby, R.; Whitehouse, R.J.S.W. Threshold of sediment motion on coastal environments. In Proceedings of the Pacific Coasts and Ports'97 Conference, Canterbury, New Zealand, 7-11 September 1997; University of Canterbury: Canterbury, New Zealand; pp. 149-154.

34. Maggi, F. Biological flocculation of suspended particles in nutrient-rich aqueous ecosystems. J. Hydrol. 2009, 376, 116-125.

35. Van der Wal, D.; van Kessel, T.; Eleveld, M.A. Vanlede. Spatial heteorgeneity in estuarine mud dynamics. Ocean Dyn. 2010, 60, 519-533. 
36. Bowers, D. A simple turbulent energy-based model of fine suspended sediment in the Irish Sea. Cont. Shelf Res. 2003, 23, 1495-1505.

37. Gourgue, O.; Baeyens, W.; Chen, M.S.; de Brauwere, A.; de Brye, B.; Deleersnijder, E.; Elskens, M.; Legat, V. A depth-averaged two-dimensional sediment transport model for environmental studies in the Scheldt Estuary and tidal river network. J. Mar. Syst. 2013, 128, 27-39.

38. Ellis, K.; Binding, C.; Bowers, D.; Jones, S.; Simpson, J. A model of turbidity maximum maintenance in the Irish Sea. Estuar. Coast. Shelf Sci. 2008, 76, 765-774.

39. Egbert, G.; Erofeeva, S. Efficient inverse modeling of barotropic ocean tides. J. Atmos. Ocean. Technol. 2002, 19, 183-204.

40. Leprêtre, A.; Chapalain, G.; Carpentier, P. A spatial interpolation method of granulometric properties of superficial sediments. Bull. Soc. Géol. France 2006, 177, 89-95.

41. Cabioch, L.; Gentil, F.; Glacon, R.; Retière, C. Le macrobenthos des fonds meubles de la Manche; distribution générale et écologie. In Biology of Benthic Organims; Keegan, B.F., Ceidigh, P.O., Caston, P.J., Eds.; Pergamon Press: Oxford, UK, 1977; pp. 115-128.

42. Vaslet, D.; Larsonneur, C.; Auffret, J.P. Map of the Surficial Sediments of the English Channel, Scale 1:500,000; Bureau de Recherches Géologiques et Minières: Orléans, France, 1979.

43. Larsonneur, C.; Bouysse, P.; Auffret, J.P. The superficial sediments of the English Channel and its western approaches. Sedimentology 1982, 29, 851-864.

44. Luyten, P.J.; Jones, J.E.; Proctor, R.; Tabor, A.; Tett, P.; Wild-Aden, K. COHERENS: A COupled Hydrodynamical-Ecological Model for Regional and Shelf Seas: Model Applications - North Sea Case Study; Report MAS3-CT97-088; Management Unit of the North Sea Mathematical Models: Bruxelles, Belgium, 1999; p. 211.

45. Rivier, A. Dynamique des Matières en Suspension Minérales des Eaux de Surface de la Manche Observée par Satellite et Modélisée Numériquement. Ph.D. Thesis in Physical Oceanography, Université de Bretagne Occidentale, Bretagne, France, 2013; p. 216

46. Service Hydrographique et Océanographique de la Marine. In Courants de Marée de Dunkerque à Brest; Imprimerie Nationale: Paris, France, 1973,

47. Menesguen, A.; Gohin, F. Observation and modelling of natural retention structures in the English Channel. J. Mar. Syst. 2006, 63, 244-256.

48. Salomon, J.C.; Breton, M. An atlas of long-term currents in the Channel. Oceanol. Acta 1993, 16, 438-448.

49. Jones, S.; Jago, C.F.; Prandle, D.; Flatt, D. Suspended sediment dynamics: Measurements and modelling in the Dover Strait. In Mixing and Transport in the Environment; Beven, K.J., Chatwin, P.C., Millbank, J.H., Eds.; John Wiley \& Sons Ltd.: New York, NY, USA, 1994.

50. Grochowski, N.T.L.; Collins, M. Wave activity on the sea-bed of the English Channel. J. Mar. Biol. Asso. UK 1994, 74, 739-742. 
51. Neumeier, U.; Ferrarin, C.; Amos, C.L.; Umgiesser, G.; Li, M.Z. Sedtrans05: An improved sediment-transport model for continental shelves and coastal waters with a new algorithm for cohesive sediments. Comput. Geosci. 2008, 34, 1223-1242.

52. IOWAGA Webpage. Available online: http://wwz.ifremer.fr/iowaga/Products (accessed on 28 April 2015).

53. LGCE Webpage. Available online: http://memphys-lgce.fr.ht (accessed on 28 April 2015).

(C) 2015 by the authors; licensee MDPI, Basel, Switzerland. This article is an open access article distributed under the terms and conditions of the Creative Commons Attribution license (http://creativecommons.org/licenses/by/4.0/). 